\title{
Risk Assessment of Agricultural Products Supply-Chain Finance Based on D-S Theory
}

\author{
Yuan Zhang1, Lian Duan'2, Gefu Zhang1 \\ ${ }^{1}$ School of Economics and Management, University of South China, Hengyang, China \\ ${ }^{2}$ The Agricultural Bank of China, Hengyang, China \\ Email: melodyflly@gmail.com
}

Received 3 August 2014; revised 10 September 2014; accepted 18 September 2014

Copyright ( 2014 by authors and Scientific Research Publishing Inc.

This work is licensed under the Creative Commons Attribution International License (CC BY). http://creativecommons.org/licenses/by/4.0/

(c) (i) Open Access

\begin{abstract}
Agricultural products supply-chain finance, as one of the solutions to the issue of "capital problems" of agriculture, countryside and farmers, has proposed a kind of characteristics model to assess the risk of agricultural production, processing and marketing, which can improve the issue of farmers and enterprises lacking of funds. This model is proposed on the basis of uncertain information processing method of D-S theory and its data combination rules, combined with the "discount rate" correction model, and it includes a risk assessment index system of agricultural products supply-chain finance, fully considering the five aspects of production, processing, marketing, cooperation of supply chain and collateral. At last, a taro supply chain is taken for example. And the risk assessment of its supply-chain finance based on this model has been discussed in detail. And the result has proved that the model and its algorithm are practical and feasible.
\end{abstract}

\section{Keywords}

Supply-Chain Finance, Risk, Agricultural Products, Taro, D-S Theory

\section{Introduction}

Being in an important period of industrialization and large-scale transformation, China's agriculture needs a lot of financial support, thus there exists a vast potential for growth in agricultural products' financial markets. It was stated by Premier Wen Jiabao in the National Finance Working Conference in January 2007 that the establishment of a rural financial system with high level, wide covering and great continuance which adapts to the characteristics of the agriculture, countryside and farmers in China should be accelerated [1]. Nowadays, however, due to such characteristics of most agricultural products enterprises as small-scale, low credit rating, and strong dependence on the environment, the bank cannot give adequate financial support for these enterprises 
considering the risks of agricultural products in the supply chain, which becomes one of the main bottlenecks retarding the development of agricultural products markets. When conducting research in the trade risk issues of some small island developing states, Federica Angelucci [2] proposed that the inadequate capacity to regulate price and production was mainly caused by the lack of horizontal and vertical cooperation among the parties in the value chain and collaboration platform support, especially the credit support. Focused on the supply-chain operations under the background of real trade, supply chain finance services link the individual members of the supply chain together to promote the allocation of risks and benefits-sharing and provide comprehensive financial services. This model, with low barriers to entry in corporate loans, has been applied widely in manufacturing, and in recent years, it has been proposed to solve the problems of inadequate financial support in the agricultural supply chains [3] [4]. However, because of the specificity and imperfection of the agricultural supply chains, the risk management and control problems still exist. Therefore, the study on the risk assessment of agricultural products supply-chain finance can not only offer help for the practice of agricultural supply chain finance businesses, but also be beneficial for banks to develop new businesses and explore new profit growth opportunities. However, the current research on agricultural products supply chain finance is just at the beginning, and the relevant practical applications are very limited, so it is of great urgency and vital importance to conduct related studies.

\section{Brief Overview on the Algorithm of D-S Theory}

Evidence can be used to distinguish and represent the major concepts such as "uncertain”, "do not know", etc. The most practical one is the Dempster-Shafer combinational rule, which can fuse lots of uncertain evidence from different sources so as to improve the accuracy of the reasoning for the event [5].

\subsection{Basic Thoughts about D-S Theory}

For a proposition, if there is a clear recognition frame $\Theta$ containing multiple discrete elements $X_{i}$ (which can contain multiple child elements $Y_{j}$ ), the understanding and awareness of each element constitute a part of the overall comprehension of it. An element can be considered as an evidence to understand a proposition, and the sufficiency of the evidence, determined by the understanding of the subject to object $x$ and the mastering degree $\operatorname{Bel}(x)$, is described with a probability value. Probability is a measure of uncertainty, a kind of risk. Therefore, as long as the uncertainty values of the individual elements in the proposition recognition frame can be identified, the overall risk characteristics of the proposition can be discerned by synthesizing the uncertainty values of various elements.

Definition 1: let $\Theta$ be the recognition frame, containing all possible independent and exclusive states of a system under consideration. The power set $2^{\Theta}$ is the set of all subsets of $\Theta(\forall x \subseteq \Theta)$, including the empty set $\phi$. Meanwhile, the theory of evidence assigns a belief mass to each element of the power set. Formally, a function $m(x) \in[0,1]$, when it adapts to the formula

$$
\begin{aligned}
& m(\phi)=0 \\
& \sum_{x \in 2^{\Theta}} m(x)=1
\end{aligned}
$$

which includes two implications: first, $|\Theta|$ is the number of dimensions for the recognition frame; second, $2^{\Theta}$ means the collection of $2^{|\Theta|}$ elements. $m(x)$ is called a Basic Probability Assignment (BPA).

Covering cross-understanding, vague understanding, totally ignorant understanding and complete understanding, the Definition 1 is closed to the realistic features of the subject's understanding to object. $m()$ is a function to describe the belief degree, called mass function. $m(X)$ refers to the degree of belief assigned in the focal elements, $m(\Theta)$ refers to the uncertainty degree of the whole proposition.

Definition 2: let $\Theta$ be the recognition frame, and when any subset of $X$ and $Y$ adapts to the formula

$$
\operatorname{Bel}(X)=\sum_{Y \subseteq X, X \subseteq \Theta} m(Y),
$$

$\operatorname{Bel}(X)$ is called the belief function of focal elements $X$.

Definition 2 clearly defined that the evidence set in a proposition, with the in-depth understanding, can be decomposed so as to adequately discern the features of the certainty of evidence from different sides. The idea is similar to the AHP-level analysis methods. $\operatorname{Bel}(X)$ represents the sum of the BPAs of all the subsets of the set $X$. 
And $\operatorname{Pl}(X)$ represents the sum of the BPAs of all the focal elements that intersect the set of $X$. Both of them are used to describe the uncertainty of focal elements $X$.

Definition 3: let $\Theta$ be the recognition frame, and when any subset of $X$ and $Y$ adapts to the formula

$$
\operatorname{Pl}(X)=\sum_{Y \cap X \neq \phi, X, Y \subset \Theta} m(Y),
$$

$P l(X)$ is called plausibility function of focal elements $X$.

Plausibility function is a method to describe the uncertainty of cross-understanding and vague understanding. When the focal elements $X$ are not intersected with others, $\operatorname{Pl}(X)$ equals $\operatorname{Bel}(X)$.

\subsection{Dempster-Shafer Combinational Rule}

In practical applications, the individual propositions discerned by lots of experts simultaneously can be used to constitute multiple information sources in order to reduce errors and avoid the bias of individual experts result from possible factors. Therefore, we should combine the multiple sets of BPAs in the same recognition frame $\Theta$. The formula

$$
m(c)=m_{i}(X) \oplus m_{j}(Y)= \begin{cases}0, & X \cap Y=\phi \\ \frac{\sum_{X \cap Y=C, \forall X, Y \subseteq \Theta} m_{i}(X) \times m_{j}(Y)}{1-K_{i j}} & X \cap Y \neq \phi\end{cases}
$$

is called the Dempster-Shafer Combinational Rule, in which $K_{i j}=\sum_{X \cap Y=\phi} m_{i}(X) \times m_{j}(Y)$, called Conflict Factors. The situation where the fusion results are always contrary to the intuitive judgment is called Zadeh Paradox.

\subsection{Dempster-Shafer Combinational Rule Based on Weighted Coefficients}

In the case of multiple evidence sources, all the evidences are treated equally in the Dempster-Shafer combinational rule, which will be bound to damage the accuracy of estimates. As a result, some researchers [6] suggested that the actual risk preferences should be taken into consideration, which is called "Discount Method". The method is as follows:

At first, to discern the importance of each set of focal elements, you can use Delphi method to constitute the weight vectors.

Then, do the normalization processing, and make sure that the normalized values are corresponding to the original weight vectors, with each value called "Discount Rate":

$$
\begin{aligned}
& m_{i}^{\prime}\left(A_{K}\right)=a_{i} m_{i}\left(A_{K}\right) \\
& m^{\prime}(\Theta)=a_{i} m(\Theta)+\left(1-a_{i}\right) \\
& \left(a_{i}=w_{i} / \max \left(w_{1}, w_{2}, \cdots, w_{n}\right), i=1,2, \cdots, n, \sum_{i=1}^{n} w_{i}=1, w_{i} \geq 0\right)
\end{aligned}
$$

Finally, according to the above formula, substitute the adjusted values of the basic belief degree of various evidences $m_{i}^{\prime}\left(A_{K}\right), m^{\prime}(\Theta)$ into the original Dempster-Shafer combinational rule, which constitutes the Dempster-Shafer combinational rule based on the discount rates.

\section{Risk Assessment Model of Agricultural Products Supply-Chain Finance}

In the agricultural products supply-chain finance model, the risk assessment of individual small businesses shifts to the operation assessment of the entire supply chain. As long as its core enterprises and the leading enterprises runs in good condition, other upstream and downstream enterprises can have a good operating base, because they can support the enterprises in trouble by collaboration, such as financial guarantees, management and technical services, so as to improve their operation situations, there by contributing to the overall development.

To assess the risk of agricultural products supply-chain finance based on evidence theory, it is essential to build the evidence recognition frame. Combined with the existing studies about the risk assessment of supplychain finance [7] [8], we will conduct the research from five aspects, the production section, processing section, 
sales section, the whole supply-chain collaboration, the core enterprises, which constitute five basic evaluation standards, considering the operational characteristics of agricultural products supply-chain, especially the impact of the environment, logistics and technology, as well as the efficiency and cooperativity of every aspect of the agricultural products supply-chain. And then, each aspect is decomposed to conduct in-depth exploration to its uncertainty. The index system and its detailed explanation is shown in Figure 1 and Table 1 below.

In the agricultural products trade, the upstream enterprises are usually the primitive production units and the shallow processing sectors, mainly dependent on the weather and logistics technology; the midstream enterprises are mainly the intermediate processing and deep processing enterprises in the agricultural supply-chain while the trade enterprises and vendors are in the downstream of the supply-chain. With large scale, those midstream enterprises generally have sound credit. It is the starting point of constructing this model to extend the impact of the credit and financial resources to the upstream and downstream enterprises and attach most importance to the coordination level in the supply chain and the ability to complete this trade successfully in examining SMEs.

Table 1. Characteristics description of the risk assessment index system of agricultural products supply-chain.

\begin{tabular}{|c|c|c|}
\hline $\begin{array}{l}\text { The first class } \\
\text { indicators }\end{array}$ & The secondary indicators & The connotation of the indexes and evaluation basis \\
\hline \multirow{3}{*}{$\begin{array}{l}\text { Production } \\
\text { section }\end{array}$} & The risk of crops & The toughness of the primary crops as well as dependence on the environment. \\
\hline & The stability of supply & Stability of procurement contracts and yields. \\
\hline & Crop quality expectations & $\begin{array}{c}\text { Quality passing rate of agricultural products, green ecology condition, } \\
\text { and quality level. }\end{array}$ \\
\hline \multirow{3}{*}{$\begin{array}{l}\text { Processing } \\
\text { section }\end{array}$} & Technical level & $\begin{array}{l}\text { Including the packaging, preservation, and other pre-processing and deep-processing } \\
\text { technology as well as the degree of mechanization and automation. }\end{array}$ \\
\hline & Management level & $\begin{array}{l}\text { Management personnel quality of related processing enterprises; whether } \\
\text { there is a sound management incentive system or not. }\end{array}$ \\
\hline & Quality security & Product quality and safety certification, etc. \\
\hline \multirow{3}{*}{ Sales section } & The stability of the sales channel & Whether it has a stable sales network. \\
\hline & Product competitiveness & The market share and the sales rate of the products. \\
\hline & Product market saturation & $\begin{array}{l}\text { The development prospects of agricultural products market as well as the } \\
\text { supply and sales situation. }\end{array}$ \\
\hline \multirow{6}{*}{$\begin{array}{l}\text { The whole } \\
\text { supply-chain } \\
\text { conditions }\end{array}$} & Informationization degree & The use of EDI, bar code, radio frequency and other modern logistics technology. \\
\hline & Standardization level & Standardization degree of packaging, handling, etc. \\
\hline & Logistics level & $\begin{array}{l}\text { Preservation technology, warehousing environment, operational efficiency, } \\
\text { the usage of the cold chain technology and equipments. }\end{array}$ \\
\hline & $\begin{array}{l}\text { Enterprise comprehensive } \\
\text { strength }\end{array}$ & $\begin{array}{l}\text { Enterprise scale, development prospects of the various areas of the supply chain, } \\
\text { including the asset size and industry position of the core enterprises, etc. }\end{array}$ \\
\hline & $\begin{array}{l}\text { Constraining force among } \\
\text { the members }\end{array}$ & $\begin{array}{l}\text { Whether a stable strategic partnership can be established among each participants; } \\
\text { cooperation with the core enterprises and the security situation. }\end{array}$ \\
\hline & $\begin{array}{l}\text { The industry's macro } \\
\text { environment }\end{array}$ & $\begin{array}{l}\text { Whether the Government is supporting the development of agricultural } \\
\text { products enterprises. }\end{array}$ \\
\hline \multirow{3}{*}{ Security situation } & The pledge & $\begin{array}{l}\text { If it is FTW or confirming warehouse financing, the stability of the collateral } \\
\text { prices, liquidity and vulnerability degree should be fully taken into account; if } \\
\text { it is accounts receivable financing, it is of vital importance to consider the } \\
\text { aging and the account period of accounts receivable and other factors. }\end{array}$ \\
\hline & $\begin{array}{l}\text { The financial situation of the } \\
\text { core enterprises }\end{array}$ & $\begin{array}{l}\text { Asset-liability ratio, cash ratio and other financial circumstances; whether } \\
\text { there are sufficient funds to guarantee the repayment section. }\end{array}$ \\
\hline & $\begin{array}{l}\text { The credit standing of the core } \\
\text { enterprises }\end{array}$ & Credit ratings of core enterprises in the bank or rating agencies. \\
\hline
\end{tabular}




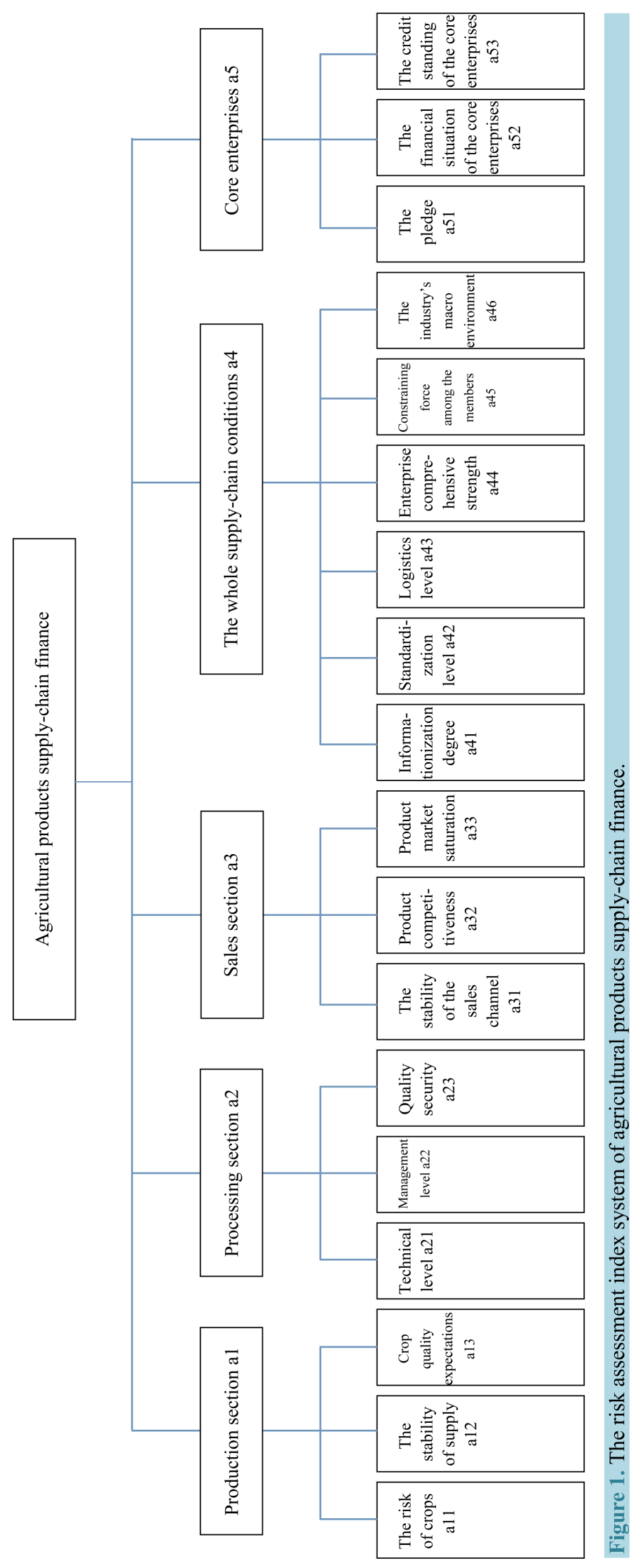


Differences in the characteristics of agricultural products can lead to those of the risks weighting on the operation of the supply-chain. For instance, the supply-chain risk of fruits and vegetables, compared with wood and wool fabric, is less affected in the processing stage but is more likely to be affected in the production stage; while the supply-chain risk of aquatic products will be affected by the impact of logistics with a relatively high proportion. To reduce the complexity, the agricultural products supply-chain in this study is mainly composed of the trade activities of 11 categories of products, including fruits and vegetables, aquatic products, meat products, tea cakes and sweetmeats, tobacco, trees and flowers, medicines, grain and oil crops, livestock, mushrooms, forest products, etc. It covers the providers of original means of production, growers, logistics enterprises, packaging and processing enterprises as well as trade and marketing enterprises. Obviously, with many sub-categories of each type, the supply-chain differs greatly in its operational risk. Therefore, it is necessary to ask experts to do assignment on the various factors of each type.

The Delphi method is used to determine the weights in this assessment index system model. The experts, involving operating personnel of agriculture bank credit departments, experts of agricultural technology sectors, marketing experts of agricultural products trade enterprises, use their experience in dealing with financial services and related businesses of agricultural products enterprises to assign the weight of each index in the agricultural products supply-chain index system, and reduce the possibility of evidence conflicts in the early stage through multiple consistent processing, such as judgment matrix construction, normalization, consistency check table, so as to increase the authority and accuracy of the weight item.

\section{Case Study}

With a tradition of planting taro, many areas in China have formed the industry, such as Lechang of Guangdong, Qidong County of Hunan, but there exist different risks in the taro cultivation, preservation and storage, processing and marketing and other sectors. The farmers adopt the way of marketing their own products with baskets; though the taro has high yields yet no harvest. For example, according to 2013's "Southern reports", the taro farmers of Lechang, Guangdong looked disappointed with the unmarketable taros due to the stagnant market. While the situation in Qidong is nothing like that of Lechang. The taro farmers there have nearly one thousand dollars more income to plant an acre of taro than to plant an acre of rice with a coalition of growers through the cooperatives and joint ventures, the financial support to the fresh storage and processing enterprises, the rapid development of deep processing and the further deepened market, which stimulated the enthusiasm of farmers to expand growing taro and made financial issues highlighted. A typical taro supply-chain includes the following sectors (Figure 2): taro seeds and fertilizer providers, taro growers, storage and shallow processing enterprises, deep-processing enterprises, wholesalers and traders and retailers. To give financial support to any enterprises, the banks not only need to examine the situation of individual enterprises, but also need to investigate the ecology of the whole chain and the management status of core enterprises.

With the changes in consumer's tastes, personality characteristics become more evident and the product diversification is in great demand. Hence, the businesses of deep-processing enterprises develop rapidly, driving the production of taro and giving strong support to the domestic and foreign trade of taro products. In this case, farmers loan from banks with the future receivables as collateral, and then the banks examine the situation of the entire chain and ultimately determine whether loan to taro farmers or not, which can also be extended to the seeds and fertilizer providers. However, as for the loan operations, how much risk do the banks face?

Based on the above mentioned risk assessment model and the application of evidence theory, the risk status of the taro supply-chain can be calculated to lay a basis for the banks' decision-making. The methods of calculating are as follows:

1) Use the Delphi method, in which several experts or credit business staffs assign the basic belief value with the related scoring criteria of the fruits and vegetables supply-chain and preset reference examples as a benchmark. Table 2 shows the assessment results from an expert.

2) Use the discount rate model, namely the Formula (5), to adjust the corresponding initial basic belief values of two indexes in Table 2 and form the Table 3. $m(\Theta)$ indicates the degree of uncertainty in the whole proposition. Actually, the basic belief value of an indicator with the most weighted index value remains unchanged, while others are assigned to $\Theta$ in proportion.

3) Synthesize the basic belief values of secondary indexes to obtain the basic belief assignment values of indicators. The results are shown in Table 4. 


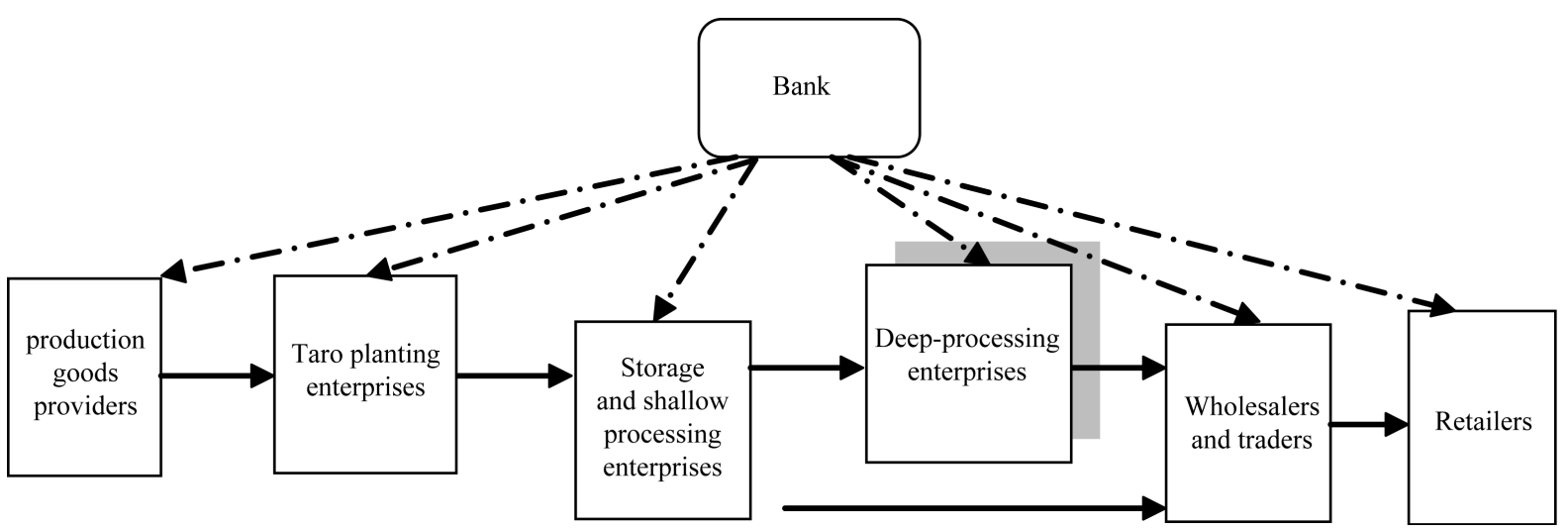

Figure 2. Taro supply-chain structures.

Table 2. Risk weights and basic belief assignment value instance of agricultural products supply-chain finance.

\begin{tabular}{|c|c|c|c|c|c|c|c|c|c|}
\hline \multirow{2}{*}{$\begin{array}{c}\text { The first class } \\
\text { indicators }\end{array}$} & \multirow{2}{*}{$\begin{array}{c}\text { Index } \\
\text { weights } W_{i}\end{array}$} & \multirow{2}{*}{$\begin{array}{l}\text { The secondary } \\
\text { indicators }\end{array}$} & \multirow{2}{*}{$\begin{array}{c}\text { Index } \\
\text { weights } \\
W_{i j}\end{array}$} & \multicolumn{6}{|c|}{ The basic belief $\beta_{i j}$} \\
\hline & & & & $\begin{array}{l}\text { Very high } \\
\text { risk } X_{1}\end{array}$ & $\begin{array}{l}\text { High risk } \\
X_{2}\end{array}$ & $\begin{array}{l}\text { Medium } \\
\text { risk } X_{3}\end{array}$ & $\begin{array}{c}\text { Low risk } \\
X_{4}\end{array}$ & $\begin{array}{l}\text { Very low } \\
\text { risk } X_{5}\end{array}$ & $\Theta$ \\
\hline \multirow{3}{*}{$\begin{array}{l}\text { Production } \\
\text { section }\end{array}$} & \multirow{3}{*}{0.1} & The risk of crops & 0.15 & 0 & 0.1 & 0.1 & 0.6 & 0.2 & 0 \\
\hline & & The stability of supply & 0.35 & 0 & 0 & 0.15 & 0.75 & 0.1 & 0 \\
\hline & & Crop quality expectations & 0.5 & 0 & 0.1 & 0.25 & 0.4 & 0.15 & 0.1 \\
\hline \multirow{3}{*}{$\begin{array}{l}\text { Processing } \\
\text { section }\end{array}$} & \multirow{3}{*}{0.1} & Technical level & 0.6 & 0 & 0 & 0.5 & 0.3 & 0.1 & 0.1 \\
\hline & & Management level & 0.25 & 0.05 & 0.1 & 0.5 & 0.1 & 0.05 & 0.2 \\
\hline & & Quality security & 0.15 & 0 & 0 & 0.1 & 0.8 & 0.1 & 0 \\
\hline \multirow{3}{*}{ Sales section } & \multirow{3}{*}{0.3} & $\begin{array}{l}\text { The stability of the sales } \\
\text { channel }\end{array}$ & 0.65 & 0 & 0 & 0.35 & 0.45 & 0 & 0.2 \\
\hline & & Product competitiveness & 0.15 & 0 & 0 & 0.1 & 0.5 & 0.2 & 0.2 \\
\hline & & Product market saturation & 0.2 & 0 & 0.1 & 0.1 & 0.4 & 0.2 & 0.2 \\
\hline \multirow{6}{*}{$\begin{array}{l}\text { The whole } \\
\text { supply-chain } \\
\text { conditions }\end{array}$} & \multirow{6}{*}{0.2} & Informationization degree & 0.1 & 0.1 & 0.1 & 0.3 & 0 & 0 & 0.5 \\
\hline & & Standardization level & 0.1 & 0.05 & 0.15 & 0.2 & 0.5 & 0.1 & 0 \\
\hline & & Logistics level & 0.45 & 0 & 0.1 & 0.4 & 0.3 & 0.1 & 0.1 \\
\hline & & $\begin{array}{l}\text { Enterprise comprehensive } \\
\text { strength }\end{array}$ & 0.2 & 0.1 & 0.2 & 0.4 & 0.1 & 0 & 0.2 \\
\hline & & $\begin{array}{l}\text { Constraining force among } \\
\text { the members }\end{array}$ & 0.1 & 0 & 0.2 & 0.3 & 0.1 & 0.1 & 0.3 \\
\hline & & $\begin{array}{c}\text { The industry's macro } \\
\text { environment }\end{array}$ & 0.05 & 0.2 & 0.2 & 0.4 & 0.2 & 0 & 0 \\
\hline \multirow{3}{*}{$\begin{array}{l}\text { Security } \\
\text { situation }\end{array}$} & \multirow{3}{*}{0.3} & The pledge & 0.6 & 0 & 0 & 0.1 & 0.2 & 0.7 & 0 \\
\hline & & $\begin{array}{l}\text { The financial situation of } \\
\text { the core enterprises }\end{array}$ & 0.2 & 0 & 0.2 & 0.3 & 0.2 & 0 & 0.3 \\
\hline & & $\begin{array}{l}\text { The credit standing of } \\
\text { the core enterprises }\end{array}$ & 0.2 & 0 & 0 & 0.2 & 0.4 & 0.1 & 0.3 \\
\hline
\end{tabular}


Table 3. The adjusted basic belief assignment of agricultural products supply-chain finance risks.

\begin{tabular}{|c|c|c|c|c|c|c|c|c|c|}
\hline \multirow{2}{*}{$\begin{array}{l}\text { The first class } \\
\text { indicators }\end{array}$} & \multirow{2}{*}{$\begin{array}{c}\text { Index } \\
\text { weights } W_{i}\end{array}$} & \multirow{2}{*}{$\begin{array}{l}\text { The secondary } \\
\text { indicators }\end{array}$} & \multirow{2}{*}{$\begin{array}{c}\text { Index } \\
\text { weights } \\
W_{i j}\end{array}$} & \multicolumn{6}{|c|}{ The basic belief $\beta_{i j}$} \\
\hline & & & & $\begin{array}{l}\text { Very high } \\
\text { risk } X_{1}\end{array}$ & $\begin{array}{c}\text { High risk } \\
X_{2}\end{array}$ & $\begin{array}{l}\text { Medium } \\
\text { risk } X_{3}\end{array}$ & $\begin{array}{c}\text { Low risk } \\
X_{4}\end{array}$ & $\begin{array}{l}\text { Very low } \\
\text { risk } X_{5}\end{array}$ & $\Theta$ \\
\hline \multirow{3}{*}{$\begin{array}{l}\text { Production } \\
\text { section }\end{array}$} & \multirow{3}{*}{0.1} & The risk of crops & 0.15 & 0 & 0.03 & 0.03 & 0.18 & 0.06 & 0.7 \\
\hline & & The stability of supply & 0.35 & 0 & 0 & 0.105 & 0.525 & 0.07 & 0.3 \\
\hline & & Crop quality expectations & 0.5 & 0 & 0.1 & 0.25 & 0.4 & 0.15 & 0.1 \\
\hline \multirow{3}{*}{$\begin{array}{l}\text { Processing } \\
\text { section }\end{array}$} & \multirow{3}{*}{0.1} & Technical level & 0.6 & 0 & 0 & 0.5 & 0.3 & 0.1 & 0.1 \\
\hline & & Management level & 0.25 & 0.0208 & 0.042 & 0.208 & 0.042 & 0.021 & 0.667 \\
\hline & & Quality security & 0.15 & 0 & 0 & 0.025 & 0.2 & 0.025 & 0.75 \\
\hline \multirow{3}{*}{ Sales section } & \multirow{3}{*}{0.3} & $\begin{array}{c}\text { The stability of the sales } \\
\text { channel }\end{array}$ & 0.65 & 0 & 0 & 0.35 & 0.45 & 0 & 0.2 \\
\hline & & Product competitiveness & 0.15 & 0 & 0 & 0.023 & 0.115 & 0.046 & 0.8615 \\
\hline & & Product market saturation & 0.2 & 0 & 0.0307 & 0.0307 & 0.123 & 0.0615 & 0.7538 \\
\hline \multirow{6}{*}{$\begin{array}{l}\text { The whole } \\
\text { supply-chain } \\
\text { conditions }\end{array}$} & \multirow{6}{*}{0.2} & Informationization degree & 0.1 & 0.0222 & 0.0222 & 0.0667 & 0 & 0 & 0.8889 \\
\hline & & Standardization level & 0.1 & 0.011 & 0.0333 & 0.0444 & 0.111 & 0.0222 & 0.7778 \\
\hline & & Logistics level & 0.45 & 0 & 0.1 & 0.4 & 0.3 & 0.1 & 0.1 \\
\hline & & $\begin{array}{l}\text { Enterprise comprehensive } \\
\text { strength }\end{array}$ & 0.2 & 0.0444 & 0.0889 & 0.1778 & 0.0444 & 0 & 0.6444 \\
\hline & & $\begin{array}{l}\text { Constraining force among } \\
\text { the members }\end{array}$ & 0.1 & 0 & 0.0444 & 0.0667 & 0.0222 & 0.0222 & 0.8444 \\
\hline & & $\begin{array}{c}\text { The industry's macro } \\
\text { environment }\end{array}$ & 0.05 & 0.0222 & 0.0222 & 0.0444 & 0.0222 & 0 & 0.8889 \\
\hline \multirow{3}{*}{$\begin{array}{l}\text { Security } \\
\text { situation }\end{array}$} & \multirow{3}{*}{0.3} & The pledge & 0.6 & 0 & 0 & 0.1 & 0.2 & 0.7 & 0 \\
\hline & & $\begin{array}{l}\text { The financial situation of } \\
\text { the core enterprises }\end{array}$ & 0.2 & 0 & 0.0667 & 0.1 & 0.0667 & 0 & 0.7667 \\
\hline & & $\begin{array}{l}\text { The credit standing of } \\
\text { the core enterprises }\end{array}$ & 0.2 & 0 & 0 & 0.0667 & 0.1333 & 0.0333 & 0.7667 \\
\hline
\end{tabular}

4) Use the discount rate model again, added to the index weights of the first class indicators. The results adjusted are as follows in Table 5.

5) Synthesize the basic belief assignment of the first class indicators. The results are as shown in Table 6.

6) Finally, use the calculation formula of the agricultural products supply-chain risk to get the risk assessment value of this agricultural product supply-chain finance. Suppose $P\left(x_{1}\right)=5, P\left(x_{2}\right)=4, P\left(x_{3}\right)=3, P\left(x_{4}\right)=2, P\left(x_{5}\right)=$ $1, P(\Theta)=3.5$, and then the supply-chain finance risk value $R$ is 1.63308. $(0 \leq R \leq 5$; the bigger $R$ is, the higher the risk is)

$$
R=\sum_{h=1}^{5} P\left(X_{h}\right) \beta=1.63308
$$

\section{Conclusions and Outlook}

According to the high, medium and low risk levels, obviously, the foregoing calculation result of risk belongs to a low risk level. Therefore, banks can loan to taro farmers, which is in line with the interests of the relevant parties. And it shows, in practice, that banks have called in loans, without bad debts. Then, the model itself and the 
Table 4. The synthesized basic belief assignment of agricultural products supply-chain finance risks.

\begin{tabular}{|c|c|c|c|c|c|c|c|}
\hline \multirow[b]{2}{*}{ The first class indicators } & \multirow{2}{*}{$\begin{array}{l}\text { Index } \\
\text { weights }\end{array}$} & \multicolumn{6}{|c|}{ The basic belief assignment } \\
\hline & & $\begin{array}{c}\text { Very high risk } \\
\qquad X_{1}\end{array}$ & $\begin{array}{l}\text { High risk } \\
\quad X_{2}\end{array}$ & $\begin{array}{c}\text { Medium risk } \\
X_{3}\end{array}$ & $\begin{array}{c}\text { Low risk } \\
X_{4}\end{array}$ & $\begin{array}{c}\text { Very low risk } \\
X_{5}\end{array}$ & $\Theta$ \\
\hline Production section & 0.1 & 0 & 0.04405 & 0.15936 & 0.66077 & 0.09525 & 0.04057 \\
\hline Processing section & 0.1 & 0.00227 & 0.00455 & 0.51921 & 0.31889 & 0.08228 & 0.07274 \\
\hline Sales section & 0.3 & 0 & 0.00634 & 0.30163 & 0.51464 & 0.02218 & 0.15522 \\
\hline $\begin{array}{c}\text { The whole supply-chain } \\
\text { conditions }\end{array}$ & 0.2 & 0.00913 & 0.10669 & 0.47366 & 0.27190 & 0.07296 & 0.06567 \\
\hline Security situation & 0.3 & 0 & 0 & 0.11085 & 0.23022 & 0.65892 & 0.00000 \\
\hline
\end{tabular}

Table 5. The readjusted basic belief assignment of agricultural products supply-chain finance risks.

\begin{tabular}{|c|c|c|c|c|c|c|c|}
\hline \multirow{2}{*}{ The first class indicators } & \multirow{2}{*}{$\begin{array}{l}\text { Index } \\
\text { weights }\end{array}$} & \multicolumn{6}{|c|}{ The basic belief assignment } \\
\hline & & $\begin{array}{c}\text { Very high risk } \\
X_{1}\end{array}$ & $\begin{array}{l}\text { High risk } \\
X_{2}\end{array}$ & $\begin{array}{c}\text { Medium risk } \\
X_{3}\end{array}$ & $\begin{array}{c}\text { Low risk } \\
X_{4}\end{array}$ & $\begin{array}{l}\text { Very low risk } \\
\qquad X_{5}\end{array}$ & $\Theta$ \\
\hline Production section & 0.1 & 0 & 0.01468 & 0.05312 & 0.22026 & 0.03175 & 0.68019 \\
\hline Processing section & 0.1 & 0.00076 & 0.00152 & 0.17307 & 0.10630 & 0.02743 & 0.69091 \\
\hline Sales section & 0.3 & 0 & 0.00634 & 0.30163 & 0.51464 & 0.02218 & 0.15522 \\
\hline $\begin{array}{c}\text { The whole supply-chain } \\
\text { conditions }\end{array}$ & 0.2 & 0.00609 & 0.07113 & 0.31577 & 0.18127 & 0.04864 & 0.37711 \\
\hline Security situation & 0.3 & 0 & 0 & 0.11085 & 0.23022 & 0.65892 & 0 \\
\hline
\end{tabular}

Table 6. The synthesized basic belief assignment of the first class indicators.

\begin{tabular}{cccccc}
\hline Very high risk $X_{1}$ & High risk $X_{2}$ & Medium risk $X_{3}$ & Low risk $X_{4}$ & Very low risk $X_{5}$ & $\Theta$ \\
\hline 0 & 0 & 0.15836 & 0.54640 & 0.29506 & 0 \\
\hline
\end{tabular}

application of evidence theory will be analyzed from the following three aspects.

1) Use D-S combinational rule to fuse the belief function assignment of the financial risks of various agricultural products supply-chains, which can draw on collective wisdom and avoid large deviations. Hence, it is more reasonable compared with the simple weighted average data processing method. As for the method, when the views are consistent, the support degree after fusion will be higher, and vice versa reduced.

2) Use D-S combinational rule based on discount rates to fuse the corresponding risk degrees of different index attribute, which has improved the limitation of equal treatment for all indexes in the D-S combinational rule and reduced the impact of highly conflicting evidence. Taking the combination of the sales sectors for example, compared with the original belief value of the secondary indicators, the adjusted result is obviously closer to the item with the largest weight ratio, and thus the belief assignment is more reasonable.

3) The risk assessment of agricultural products supply-chain finance covers many factors in the supply-chain and problems of various sectors such as the complex risk assessment indicators and the uncertainty of information sources, which are also difficult to quantify. Besides, what it involves mostly are the small and medium enterprises, even individual farmers, which lead to the lack of financial data and credit records, and as a result, it is difficult to obtain complete and accurate data in the data acquisition and processing. However, when initially used, the evidence theory does not require very precise quantitative information, and the fuzzification method can be applied to deal with the uncertainty of various scenarios, such as constructing the membership model. Therefore, this model has strong adaptability.

However, the above model and the calculation method also have some flaws. On one hand, the calculation of risks doesn't fully consider the characteristics of prospective borrowers. Taking taro farmers for example, their 
characteristics cannot be ignored because processors can reselect suppliers to reconstruct the taro supply-chain. On the other hand, for banks, because of the multiple types and various features of agricultural products, it is difficult for those loan officers who are unfamiliar with the product characteristics to carry out the work in an artificial way. So it is of vital importance to develop effective tools to support classification, calculation and analysis. This is our future research work.

\section{References}

[1] Zhou, C. (2012) Build a Policy Support System and Fill the Blank of the Financial Services. Financial Times, 28 August 2012.

[2] Angelucci, F. and Conforti, P. (2010) Risk Management and Finance along Value Chains of Small Island Developing States. Evidence from the Caribbean and the Pacific. Food Policy, 12.

[3] Yang, J.R. (2013) The Strategic Choice of Rural Financial Product Innovation Based on the Financial Perspective of Supply Chain. Finance and Economics, 3.

[4] Y. Wang, (2012) Do a Good Job in Financial Support of Agricultural Products Supply Chain. Securities Times, 27 December 2012.

[5] Li, B. and Pang, F.-W. (2013) An Approach of Vessel Collision Risk Assessment Based on the D-S Evidence Theory. Ocean Engineering, 12.

[6] Gao, H.S. and Zhu, J. (2008) A Kind of Network Security Risk Assessment Model Based on D-S Evidence Theory. Computer Engineering and Applications, 6.

[7] Li, Y.X. (2011) Supply Chain Finance Risk Assessment. Journal of Central University of Finance and Economics, 10.

[8] Tian, J.H. (2013) Supply Chain Finance and Its Credit Risk Control. Zhejiang Industry and Commerce University, Hangzhou. 
Scientific Research Publishing (SCIRP) is one of the largest Open Access journal publishers. It is currently publishing more than 200 open access, online, peer-reviewed journals covering a wide range of academic disciplines. SCIRP serves the worldwide academic communities and contributes to the progress and application of science with its publication.

Other selected journals from SCIRP are listed as below. Submit your manuscript to us via either submit@scirp.org or Online Submission Portal.
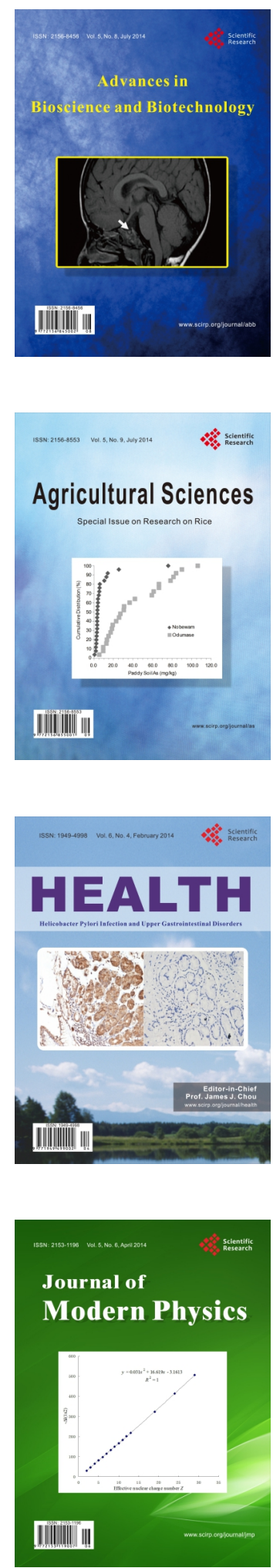
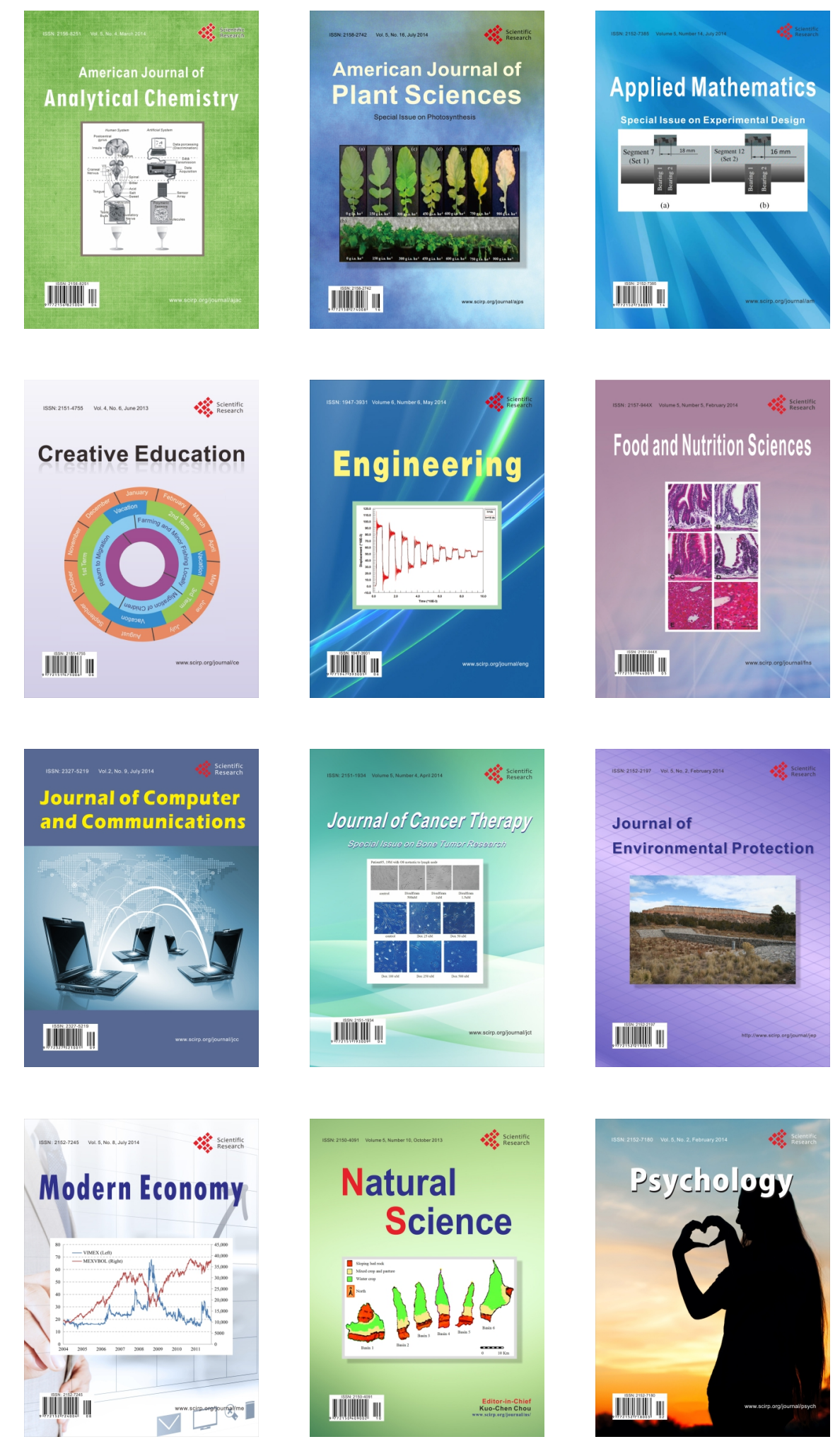